\title{
LA UTILIDAD Y LA JUSTICIA SEGÚN JOAQUÍN COSTA, UNA VISIÓN ANTICIPADA DEL ANÁLISIS ECONÓMICO DEL DERECHO (AED)
}

\section{Utility and Justice according to Joaquin Costa, an Advance View of the Economic Analysis of Law (AED)}

\author{
Rafael Bernad Mainar ${ }^{1}$ \\ Universidad San Jorge (USJ) \\ E-mail: rbernad@usj.es
}

Autor

Una mente tan privilegiada como la del polígrafo aragonés Joaquín Costa que, lo mismo transitaba por la historia, la literatura, la geografía, la pedagogía, la antropología, la agricultura, la economía, la política o el derecho, pudo entrever la interrelación entre las distintas disciplinas del saber. Costa, adelantándose una vez más a su tiempo, conecta el derecho y la economía para alertar del posible conflicto entre la justicia y la utilidad.

En nuestros días, gracias a la presencia del análisis económico del derecho (AED), ese conflicto sigue vivo bajo los términos del binomio eficiencia-equidad, y se erige en una de las claves para explicar y diseñar el derecho a través de una perspectiva económica, ante el reto de satisfacer un amplio abanico de necesidades en el marco de unos recursos limitados, que hay que administrar y dosificar adecuadamente.

El mérito de Costa en este tema radica, por un lado, en haber detectado este punto de fricción como base de los problemas padecidos en la España de la época; y, por otro, en acertar al plantear la regeneración del equilibrio perdido por medio de la justicia, en una sociedad frecuentemente guiada por un mal entendido principio de utilidad.

A mind as privileged as that of the Joaquin Costa Aragonese polygraph who, the same went through history, literature, geography, pedagogy, anthropology, agriculture, economics, politics or law, could glimpse the interrelation between the different disciplines of knowledge. Costa, ahead of his time once again, connects the law and the economy to warn of the possible conflict between justice and utility.

Nowadays, thanks to the presence of the economic analysis of law (AED), this conflict is still alive under the terms of the efficiency-equity binomial, and stands as one of the keys to explaining and designing law through

\footnotetext{
1 Investigador Principal del Grupo de Investigación ECONOMIUS-J (USJ), Código de Referencia S03_20D. Investigador Asociado del Instituto de Investigaciones Jurídicas de la Universidad Católica Andrés Bello (UCAB).
} 
an economic perspective, faced with the challenge of satisfying a wide range of needs within the framework of limited resources, which must be managed and dosed appropriately.

Costa's merit in this matter lies, on the one hand, in having detected this point of friction as the basis of the problems suffered in Spain at the time; and, on the other, to succeed in proposing the regeneration of the lost balance through justice, in a society frequently guided by a misunderstood principle of utility.

Joaquín Costa; derecho; economía; utilidad; justicia; análisis económico del derecho

Joaquin Costa; law; economy; utility; justice; economic analysis of law

\section{Introducción}

Cuando hablamos de Joaquín Costa en la actualidad procede llevar a cabo una necesaria labor de encaje y adaptación, toda vez que el encuadre y análisis de un personaje propio del siglo XIX en pleno siglo XXI nos compele a realizar una serie de ajustes para contar con una comprensión más acertada a la hora de calibrar la dimensión de una figura de su talla intelectual y proyección histórica.

En primer lugar, hemos de partir de la idea de que el prototipo del hombre ilustrado y polifacético que acompañó a eximios protagonistas históricos, hasta el punto de llegar a ser calificados como polígrafos, choca abiertamente con la tendencia y cristalización de otro prototipo más actual, cual es el hombre experto en una rama del saber concreta (Cheyne, 1987, p. 3), como reflejo de un fenómeno cada vez más arraigado y consagrado que es el de la especialización, elevado a la categoría global de paradigma digno de encomio por su gran utilidad.

Ante la atonía cultural generalizada de una población en buena parte iletrada, los siglos XVIII y XIX propiciarán que aquellos que cuentan con una mayor preparación y la avidez por saber y conocer cada día más, realicen propuestas de mejora de la sociedad, precisada en aquellos tiempos de avances sustanciales en aras de la medra en lo que a sus condiciones más elementales de vida se refería.

Este el caso que aquí nos incumbe, puesto que el insigne Joaquín Costa encarnaba a la perfección la cualificación polifacética en lo que al ámbito intelectual concernía: en efecto, su obra y vida se paseó por distintos escenarios que, lejos de distanciarse y configurarse como compartimentos estancos, lograban conectar bajo el manto del regeneracionismo social ante los males y flagelos que carcomían un sistema sediento de reformas depuradoras.

En este periplo intelectual, Costa cultivó, fundamentalmente, el campo de las ciencias humanas y sociales (geografía, historia, literatura, lingüística, derecho, sociología, educación, etnología, antropología, economía) e, incluso, algunas de corte más experimental (la agricultura y la ingeniería, enfocada esta última a las técnicas de riego agrícolas), sin pasar por alto el interés y la participación en la política nacional, como lo demuestra el hecho de la multi- 
plicidad de escritos elaborados ${ }^{2}$, así como su inserción en el plano internacional al abordar el tópico del colonialismo y sus implicaciones, coincidiendo con los últimos estertores del glorioso pasado colonial español. Precisamente, la amplia variedad de los temas estudiados por Costa, fruto de una avidez intelectual sin límites, le ha granjeado críticas de un mal entendido enciclopedismo y de gran dispersión en su obra (Gómez Benito \& Ortí Benlloch, 1996, p. 38); sin embargo, si analizamos en profundidad toda su vasta creación intelectual, podremos constatar que tales imputaciones son en buena parte superficiales, toda vez que la pretendida diseminación imputada no es sino el resultado de desarrollos parciales de un mismo proyecto intelectual y político, dotado de unidad y de coherencia.

Entre sus inquietudes más sobresalientes destaca la pasión que mostró por el problema de la educación en España ${ }^{3}$ al entender que no cabía la regeneración del país sin la mejora significativa del nivel y calidad de la educación. Precisamente y, en la línea de su cualidad de polígrafo, defiende la formación integral del ser humano, incluida la de la mujer, así como pone especial hincapié en la educación primaria, la del mundo rural y la implementación de una educación popular y permanente basada en la puesta en práctica de misiones pedagógicas, nuevas experiencias metodológicas (talleres, excursiones), la cooperación entre el maestro y la familia, y la formación a través de los ejemplos ilustrativos. Criterios todos ellos defendidos en la fundación y puesta en marcha de la Institución Libre de Enseñanza (Cheyne, 1992, pp. 127 y ss.), en la que participó de la mano de su fundador Giner de los Ríos, a la sazón profesor y amigo suyo.

También mencionaremos su faceta literaria (Mainer Baqué, 1987, pp. 11-16), pues aun cuando no fuera la más conocida ni la más destacada, constituyó una de sus pasiones juveniles que retomó en su etapa final como consecuencia de la frustración en sus incursiones en la política y en la vida pública ${ }^{4}$. La mayor parte de sus inquietudes quedarán plasmadas en proyectos bosquejados con meros títulos o esquemas bajo dos itinerarios: por un lado, la poesía narrativa histórica vertida en prosa ${ }^{5}$; y, por otro, la novela con visos de anticipación científica ${ }^{6}$. Siguiendo la estela de Benito Pérez Galdós, Costa ideó unas Novelas nacionales que, con un objetivo pedagógico y un ideario patriótico liberal, permitieran recorrer la historia de España desde el mítico desembarco de Aquiles en Iberia hasta el final del trienio liberal iniciado con el levantamiento de Riego en Cabezas de San Juan, que pondría fin al Sexenio absolutista de Fernando VII.

\footnotetext{
2 Costa Martínez (2005).

3 Entre 1869 y 1870 escribe obras relacionadas con la educación, entre las que destacan El maestro y el sacerdote, Apuntes para la exposición de un método general de enseñanza, Ensayo sobre fomento de la educación popular, Nueva base de la educación.

4 De esta última etapa vital incluimos la obra Ultimo día del paganismo y primero de ... lo mismo, en la que narra a través de su protagonista, Numisio, el escenario de la Hispania romana bajo el mandato del emperador romano Teodosio.
}

5 Algunos títulos que revelan meras intenciones y proyectos poéticos sin textos acabados se reflejan en la siguiente enumeración: Carlos VII en el trono; Hernán Cortes, Hernando o la castidad del corazón, El Sinaí o los hebreos; Melodias.

6 En este apartado destaca la obra El siglo XXI, en la que su protagonista, Justo, fue enterrado vivo por error en el siglo XIX y logra despertar en pleno siglo XXI (año 2075). 
En el plano político, Costa se diferencia del resto de los intelectuales de su época en que es un hombre de acción y, por tanto, no elude su participación en la política del momento, hasta el punto de elaborar credos ideológicos y crear organizaciones políticas para llevarlos a la práctica. En ese ámbito destaca, más si cabe, su talante crítico y reformista de la sociedad y de la economía española. Por ello, expresará su disconformidad con el proceso de la desamortización; se expresará en contra de una política agraria basada en una oligarquía terrateniente; despotrica de la clase política y de la administración, corrompidas por las manipulaciones y fraudes electorales ${ }^{7}$, lo que le alejará, tanto de los partidos tradicionales que mantienen el sistema del turnismo político (partido liberal y conservador con sus líderes al frente, Sagasta y Cánovas del Castillo, respectivamente), como de las recientes organizaciones obreras, situación que le llevará a crear algunos movimientos de nuevo cuño e integrar algunas organizaciones políticas ${ }^{8}$ con escaso éxito y predicamento. El carácter apasionado, controvertido y visceral de Joaquín Costa ha dado pie a la interpretación de sus ideas políticas, tanto en una línea de aproximación al marxismo, cuanto en el abanderamiento de soluciones mesiánicas y dictatoriales, fruto en ambos casos de lecturas sesgadas y asistemáticas (Navarro Rubio, 1994, p. 25).

Su faz más sociológica en el ámbito jurídico le llevó a conectar con aspectos de la antropología social (Del Pino Díaz, 1987, pp. 28-32), la etnografía y la filología, sobre todo la dialectología, a través del método comparativo entre distintos pueblos a lo largo de distintas épocas históricas.

Tampoco podemos omitir su vertiente de economista, de la que nos ocuparemos más adelante, en la medida que Costa reconoce la incidencia de la economía en la transformación de una sociedad atrasada como la española (Fernández Clemente, 1987, pp. 22-25). Su origen aragonés propició un gran interés por la agricultura y el mundo rural, teniendo en cuenta que en su época la base de la economía era la agricultura, lo que le alentó en el estudio de la ingeniería hidráulica y la técnica de los riegos, sobre el entendido de que el agua constituía la verdadera simiente y el maná del agro español.

Por fin y, a título de inventario, mencionaremos la vertiente jurídica de Joaquín Costa (en su polifacética cualidad de abogado, notario, asesor legal y teórico del derecho), que se verá amputada de algún modo por el veto excluyente que las autoridades universitarias le infligieron en su intento y vocación de impartir docencia en la universidad. Constituye el terreno jurídico, sin lugar a dudas, el más prolífico y extenso de su obra, desde distintas perspectivas, en función de la temática abordada (ya la teoría del derecho, ya la sociología jurídica, bien el derecho consuetudinario, o bien, por fin, el derecho foral aragonés).

\footnotetext{
7 Su obra Oligarquía y Caciquismo como la forma actual de gobierno en España expresa bien a las claras este sentimiento.

8 Liga de Contribuyentes de Ribagorza (1891), que amplía su espectro más tarde como Cámara Agrícola del Alto Aragón (1892) y Liga Nacional de Productores (1899). Esta última integró el movimiento de la Unión Nacional (1900), que fracasaría, no obstante representar el primer conato de incorporar en la vida pública a las denominadas clases neutras.

Costa resultó electo diputado por la Unión Republicana en 1903, pero declinó el nombramiento como acto de protesta contra el sistema político. Si bien criticaba a la oligarquía terrateniente y al sistema parlamentario como pilares del statu quo imperante, también mostró recelo respecto de los movimientos y organizaciones sindicales, puesto que su proyecto se basaba en clases medias con aspiraciones reformistas.

Sobre el particular, Forcadell Álvarez (1987), pp. 25-28.
} 


\section{Joaquín Costa y el regeneracionismo}

El movimiento del regeneracionismo español se sitúa cronológicamente en la última década del siglo XIX y los primeros años del siglo XX. Su campo de cultivo abonado coincide con un momento convulso de la historia patria en el ámbito político, económico y social, que se traducirá en una serie de manifestaciones de índole ideológico y cultural, cuyo resultado arrojaría nuevos planteamientos, análisis y perspectivas frente a dicha coyuntura. A ello habría que añadir por su especial simbolismo y la conmoción ocasionada en la sociedad española, hasta el punto de constituir el espejo de frustración del momento histórico, el denominado "desastre del 98" con la pérdida de la isla de Cuba, a la sazón último bastión del glorioso pasado colonial español.

Algunos años atrás, la influencia del krausismo ${ }^{9}$ y del positivismo ${ }^{10}$ caló en la clase media intelectual española, a lo que habría de sumarse el desarrollo de las ideas proletarias y la aparición de los primeros embates del movimiento obrero en la vida nacional, que contrasta con el statu quo reinante de la Restauración monárquica representado en lo político por la vigencia del turnismo de partidos, y en lo social por el protagonismo de la oligarquía y el caciquismo. Fruto de este contexto, podemos ubicar la crisis de fin de siglo, delimitada entre los 1890 y 1910 (Lissorgues, 1998, pp. 46 y ss.), como el escenario histórico en el que se enmarca el movimiento regeneracionista español, abanderado por algunas publicaciones emblemáticas que se identifican con é ${ }^{11}$, que se hacen eco del clima de crisis generalizada, incluido el de la conciencia nacional.

Tanto los intelectuales, como la pequeña burguesía y las clases medias — clases neutras o masa neutra en palabras de Costa (Forcadell Álvarez, 1987, p. 27; Cheyne, 2010, p. 140)—, aúnan sus fuerzas contra el régimen de la Restauración, a la vez que tratan de neutralizar el riesgo de la revolución del proletariado, que no es "su revolución” (Costa Martínez, 1981, pp. 35 y ss.), tras el fracaso de la revolución burguesa en España. Aun así, en este frente regeneracionista surgen diversas orientaciones, más o menos radicales (burguesa, pequeño burguesa, socialista o anarquista). En este cuadro histórico, el regeneracionismo representa una arista del movimiento general de regeneración, y la literatura regeneracionista constituye, de entre todas las distintas direcciones del movimiento, la más sobresaliente. Es aquí donde entra en juego y descuella la figura de Joaquín Costa (Chacón Delgado, 2013, pp.

\footnotetext{
9 El krausismo otorga un papel preponderante al movimiento de las asociaciones (religiosas, científicas, artísticas, industriales, morales, jurídicas, económicas) que deben constituirse y desarrollarse para alcanzar toda clase de fines, reduciendo con ello la intervención del Estado, cuyo espacio de actuación quedaría constreñido al estrictamente político y al mínimo necesario de la vigilancia para evitar solapamientos e interferencias entre las asociaciones creadas según sus respectivos fines. Sobre el particular, Capellán de Miguel (1998), pp. 137-153.

10 El positivismo constituye un movimiento dirigido a la creación de un orden social. En tal sentido, el saber positivo se erige en la conditio sine qua non de toda autoridad social, lo que vincularía la historia con el positivismo. Augusto Comte, padre del positivismo, pretende replicar el estudio de la humanidad colectiva y convertirlo en ciencia positiva, en cuya virtud en la sociedad rigen los tres estados con sus respectivas etapas (estado teológico o mágico relacionado con la sociedad militar; estado metafísico correspondiente a la sociedad económica; y estado científico o positivo, propio de la sociedad industrial). Un estudio amplio y profundo del positivismo, más que recomendable, lo encontramos en Kremer-Marietti (1980).
}

11 En este sentido podemos destacar, entre otras, la obra de Lucas Mallada (1890) Los males de la patria y la futura revolución española. Consideraciones generales acerca de sus causas y efectos, y también la de Joaquín Sánchez de Toca (1912) Reconstitución de España en vida de economía política actual. 
33 y ss.), pues no solo se trata de uno de los escritores más representativos de la literatura regeneracionista junto a Lucas Mallada y Macías Picavea, sino que, a la postre, se erige en el personaje más emblemático del movimiento regeneracionista español.

Sus amplios conocimientos le permitirán confeccionar una vasta obra sobre los más diversos y heterogéneos tópicos (López Medel, 1994, p. 47), aglutinados todos ellos en torno a la pasión y el dolor por España ante los problemas que aquejan al pueblo (Martínez Val, 1994, pp. 31, 40, 42), y la necesidad de realizar propuestas para regenerarla mediante un cambio liderado por las clases medias, verdadero antídoto frente al conservadurismo recalcitrante y el proletariado emergente.

En efecto, Costa, a partir de un diagnóstico crítico de la sociedad española (López Medel, 1994, pp. 53-54), señala sus verdaderas lacras (la carencia de libertad y de soberanía; un sistema político parlamentario que enmascara un régimen oligárquico y caciquil; la atonía y pasividad del pueblo), y presenta unos postulados regeneracionistas destinados a erradicar las taras para lograr con ello la resurrección, entre los cuales destacan (López Medel, 1994, pp. 54-58): el fomento intensivo y reforma de la educación; el estímulo exhaustivo de la producción y de la distribución del bienestar social; el reconocimiento de la personalidad y del protagonismo del municipio; la independencia del poder judicial y la potenciación del arbitraje como solución alternativa de conflictos; la europeización de España sin menoscabo de su identidad; la participación y compromiso de los intelectuales en la vida pública; la creación de una legislación social; la mejora de las obras públicas. En suma, la encarnación en estado puro de un regeneracionismo populista, abierto, creador y con perspectivas.

Tanto es así que, en muchas ocasiones, Costa proyecta una sensación de frustración e impotencia rayana con el pesimismo, lo que propiciará la evocación de un pasado glorioso y mitológico, con tintes mesiánicos, solo capaz de ser reeditado a través de la irrupción del hombre providencial, un "cirujano de hierro" (Vallet de Goytisolo, 1994, p. 16) que aplique una política quirúrgica de choque para revertir la situación mediante una revolución.

\section{Joaquín Costa: una visión particular del derecho}

La visión que Joaquín Costa aporta sobre el derecho, rondando en muchas ocasiones los predios de la filosofía del derecho, puede ser extraída, fundamentalmente, de las obras La vida del derecho (1876), Teoría del hecho jurídico individual y social (1880), y su discurso de ingreso en la Academia de Ciencias Morales y Políticas (3 de febrero de 1901), que versó sobre El problema de la ignorancia del derecho y sus relaciones: el status individual, el referéndum y la costumbre ${ }^{12}$.

En tales obras se detecta en Costa una clara huella del ideario krausista imbuido por medio de su maestro Giner de los Ríos y, especialmente en la segunda de ellas, la influencia del positivismo jurídico (Bobbio, 2018, pp. 81 y ss.), movimiento muy en boga en el momento, que va ganando terreno en nuestro país tras la conclusión del periodo codificador, pendiente todavía de consumar con la codificación civil.

Cuando Costa pretende indagar sobre el concepto del derecho, lejos de reducirlo al criterio acuñado por la ciencia escolástica, que aporta una visión reflexiva del mismo, añade

12 Biblioteca Virtual Miguel de Cervantes. 
la necesidad de incorporar un concepto inmediato basado en el sentido común. A tal fin, parte de la distinción entre lo que piensa sobre el derecho la conciencia científica y lo que dicta la conciencia común, ante la más que usual divergencia existente entre el saber común y la ciencia escolástica, puesto que, en muchas ocasiones, se presentan como antinomias irreductibles al estar basadas, respectivamente, en la razón científica y en la razón común, pronunciándose en tal sentido Costa más partidario de la segunda que de la primera, si bien reconociendo su complementariedad, dado el cariz más reflexivo de la primera e inmediato de la segunda (1876, p. 47), pues "lo subjetivo e ideal de la una se corrige con el carácter positivo de la otra, y lo inseguro e indeterminado de esta con el tono categórico de aquella”.

A partir de estas consideraciones, Costa nos muestra que la esencia del derecho radica en la relación existente entre los fines racionales de la vida y las condiciones que deben prestar para su cumplimiento los sujetos racionales y libres; en otras palabras "la Conducta libre en cuanto presta Medios para Fines racionales". A partir de tal noción, los elementos del Derecho son: "un sujeto, en quien determinadamente residan los fines; un objeto, constituido por utilidades concretas capaces de servir como medio a aquellos fines; y una actividad libre y conscia que sirve de vínculo inmediato entre sujeto y objeto, aproximando las utilidades radicadas en éste a los fines dados en aquél" (1876, p. 58), identificados, respectivamente, como condicionado (sujeto), condiciones (objeto) y condicionante (sujeto activo mediador, que suele ser el mismo condicionado).

De la misma manera que el hombre cuenta con un componente individual y social, también el derecho, según Joaquín Costa, presenta esa doble vertiente: en efecto, en la medida que

[...] los fines se dan en cada hombre y los medios en él o fuera de él, la relación jurídica será unas veces interior y exterior otras, existirán por tanto dos esferas de Derecho, la esfera Inmanente o Individual, en la cual aparecen conjuntamente los fines y los medios como medios y fines míos que yo mismo como sujeto activo debo libremente relacionar, y la esfera transitiva o social en la cual los medios han de ser prestados por otro sujeto que aquél en quien radiquen los fines, y cuya relación por tanto toca inmediatamente a él como individualidad activa, libre y obligada, y mediatamente a mí que debo una segunda prestación, ya inmanente, si la naturaleza de la condición la requiriese, para asimilarla a mi necesidad y dejarla satisfecha. (1876, pp. 62-63)

Ante la necesidad de conectar el derecho con la sociedad, en un adelanto de lo que sería su visión sociológica del derecho, Costa aborda su concepción sobre la vida en general como un preámbulo necesario antes de desembarcar posteriormente en lo que se refiere a la vida jurídica o del derecho. Siguiendo con la metodología ya empleada en la indagación sobre la noción del derecho, parte de la diferenciación entre el concepto escolástico y el derivado del sentido común (1876, pp. 65 y ss.), mostrándose al efecto más próximo de la segunda acepción —Razón natural—, que de la primera — Razón científica-, hasta el punto de llegar a señalar que la vida constituye la "actividad de los seres en cuanto informa o hace real y efectiva en Hechos o estados su Esencia eterna y cada una de sus propiedades”, entre cuyos elementos se desgrana la esencia posible o potencia (lo factible, la idea), lo positivo o la esencia puesta en estados (lo hecho), y la actividad vital del ser que vive que causa los estados (el agente).

En cuanto a las leyes que rigen la vida, emerge con fuerza en Costa la "Ley del Bien, suprema, y por lo mismo única; si existen otras, estarán subordinadas a ella y para su servicio", de tal manera que "del concepto mismo de la Vida se infiere que el bien es su fin o uno de sus 
fines, lo mismo cuando se dirige a producir hechos originalmente, como cuando tiende a sanarlos y restituirlos al orden reparado de la esencia" (1876, pp. 86, 87 y ss., 121 y ss.). A partir de ahí, el resto de las leyes se rigen bajo el principio del desenvolvimiento de dicho Bien y se clasifican según ciertas categorías, en función del criterio de la esencia unida a la forma (leyes de la mudanza, de la permanencia, del progreso) y del criterio de la actividad (leyes reales o esenciales, formales y orgánicas).

Para cerrar el círculo, Joaquín Costa entreteje una relación entre ambos conceptos — derecho, vida-, y muestra su visión del derecho, abordando el tópico relacionado con la vida del derecho, esto es, "la composición de sus dos formas originarias de existencia (permanente y temporal) en una tercera, mediante la actividad del ser de quien el Derecho es una propiedad ..." (1876, pp. 93 y ss.), concepto que evidencia tres aspectos relevantes: uno, el derecho por vivir o factible; otro, el derecho vivido o efectuado; y otro, subjetivo, la actividad eficiente que media entre ellos. Por su través, se engarza con los términos de un silogismo: la premisa mayor, constituida por el derecho ideal o posible — derecho natural-; la premisa menor, representada por el agente o gestor que desarrolla esa idea típica; y, por último, la conclusión, el derecho positivo o histórico, fruto de esta evolución del Derecho eterno enmarcado bajo la estructura del silogismo.

Entre ambos extremos conciliables, el derecho natural y el positivo, la actividad jurídica aparece como elemento mediador (1876, p. 117), que se regirá del siguiente modo (1876, pp. 118, 121, 124 y ss.): a) por leyes supremas, ya de corte objetivo, como es la consecución del Bien común, ya subjetivo, en su relación con el Estado, cual es la libertad individual, que sostiene la actuación consciente y libre del individuo, y que debe ser cuidadosamente distinguida del albedrío; o b) por leyes particulares, bien objetivas (reales, formales, realesformales) o subjetivas (reales, formales, orgánicas).

Como expresión del derecho vivo, Costa se refiere a la norma jurídica o regla de derecho, a la que define como "la forma general en que se expresa el derecho al particularizarse en cánones concretos para el régimen libre de la vida" (1876, pp. 138 y ss.), clasificada de formas particulares y fundamentadas en aquello que sirve para determinarlo como derecho positivo. A su vez, nos presenta las dos formas originarias y sustantivas que dentro de la ley jurídica encuentra el análisis, a partir de la naturaleza de la actividad que particulariza el derecho ideal para darle existencia positiva: por un lado, la ley espontánea y, por otro, la ley reflexiva; en otras palabras, la costumbre y el ordenamiento. Con relación a este último, Costa clasifica las formas del derecho positivo según sus respectivas funciones: leyes normales (función declarativo-legislativa, ejecutivo-administrativa, o reguladora); o leyes anormales (función declarativo-judicial y ejecutivo-reparadora).

En otro lugar de su extensa obra jurídica, Costa resume las notas que caracterizan el derecho al conectarlo con una serie de principios que lo informan, ya de forma positiva, o bien por medio del argumento en contrario (1880, p. 51):

1. El derecho constituye un principio de dirección para la voluntad, independiente de la voluntad y, a la vez, superior a ella.

2. Supone también un principio de libertad, cuya realización depende de la libre aceptación del sujeto racional, de tal manera que el derecho solo vive en la libertad (Martínez Val, 1994, pp. 38 y 39), premisa que atribuye a la coacción, según Costa, la cualidad de factor accidental de la vida del derecho, y no de un componente del mismo. 
3. Representa un principio de beneficencia, que consiste en ejecutar libremente algún bien, un espacio abonado para comulgar con la moralidad.

4. Incluye un principio de condicionalidad, lo que lo separa de la moralidad (1880, pp. 37-40), ya que no ejecuta el bien sustantivamente, por el bien mismo, sino para servir a otro bien, esto es, como medio o condición que cumpla algún fin a que el hombre viene obligado por su misma naturaleza.

5. Incorpora un principio de racionalidad, lo que lo diferencia de la mera relación de utilidad, pues no todos los medios ni todos los fines tienen un alcance jurídico. Por tal razón y, en la medida que el derecho representa una forma racional de la vida entera, no puede encerrarse en sistema normativo alguno (Vallet de Goytisolo, 1994, p. 17).

6. No es un principio de reciprocidad, toda vez que el mutuo respeto, el intercambio de utilidades y servicios es una consecuencia del derecho, pero no lo constituye, de ahí que sea independiente de la reciprocidad, según veremos después.

En suma, Costa, en consonancia con la estructura krausista de su pensamiento, atribuye al derecho una suerte de misión salvadora (Gil Novales, 1965, pp. 11-21; Gómez Benito \& Ortí Benlloch, 1996, pp. 31-32), lo que se traduce a la hora de pergeñar y diseñar la revolución regeneracionista en situar al derecho como uno de los bastiones fundamentales, junto a otros también esenciales (educación y despensa) en el arduo camino y proceso de regeneración nacional.

\section{La economía según Joaquín Costa}

Son varias las incursiones de Joaquín Costa en lo que a la economía se refiere y en temas tan diversos como la política colonial y sus repercusiones económicas, o la agricultura en su conjunto (producción agrícola, política hidráulica, explotación de las tierras, asociacionismo y colectivismo).

En efecto, uno de sus temas predilectos fue la colonización africana, traducido por escrito en la obra El comercio español y la cuestión de África, en la que reflejará su posición respecto de las consecuencias económicas de la política colonial española, y se muestra partidario de conciliar, por un lado, los intereses políticos y económicos del país colonizador, en este caso España, con la necesidad del respeto de los derechos humanos, la cultura, la sociedad y la tradición de los pueblos autóctonos colonizados.

A ello habría que añadir su afán por el tema de la promoción de la agricultura ${ }^{13}$, principal bastión de la economía en su época, a pesar de la crisis agrícola y ganadera nacional del momento ante la llegada masiva de productos extranjeros a precios más bajos. Frente a tal situación, Costa entiende con razón que la agricultura y la ganadería precisan de una política hidráulica que acompañe e impulse la reactivación de estos sectores de la economía (Ballarín Marcial, 1994, pp. 102-109). A tal fin, Costa atribuye el carácter de misión social a

$13 \mathrm{Al}$ respecto, Agricultura armómica (1877); sus discursos en los Congresos de Agricultores y Ganaderos (Madrid, 1880 y 1881); Política Hidráulica (Misión social de los riegos en España) (1911). 
la implantación del regadío en España, no solo como solución al flagelo de la aridez secular de una gran parte del campo español, sino también como necesidad de alcanzar una mayor productividad de las tierras con miras a la consiguiente mejora de las condiciones de vida del agro español y, más concretamente, de los pequeños campesinos y trabajadores agrícolas, con el objetivo de contrarrestar el éxodo rural. En esa línea de pensamiento y opinión, Costa defiende con tesón y pasión desde finales del siglo XIX las bondades del cooperativismo agrícola (Sanz Jarque, 1994, pp. 72-74), un instrumento básico del ideario krausista impulsor del regeneracionismo español, que, sorprendentemente y, según podemos comprobar en nuestros días, constituye uno de los ejes esenciales sobre los que sigue gravitando el sistema agrícola europeo y español del siglo XXI.

Sin embargo, su obra cumbre en materia económica es Colectivismo agrario en España (1898) que, en su primera parte, constituye una completa presentación histórica del pensamiento económico desde el Renacimiento hasta el siglo XIX, en tanto que la segunda parte de la obra introduce un trabajo minucioso y bien documentado de experiencias colectivistas agrarias en España (entre ellas los pastos comunes, o el sorteo y explotación de tierras comunales).

Entre sus ideas económicas, en general, Costa propone (Fernández Clemente, 1994, p. 24) un encauzamiento del presupuesto nacional en áreas prioritarias como la educación, el impulso de la colonización interior, la política hidráulica, la repoblación forestal, o la investigación científica; el abaratamiento de los precios del pan y de la carne merced al incremento de la producción y el impulso del crédito agrícola; la mejora de las comunicaciones terrestres; la implantación de una legislación social (seguro social, ahorros para la vejez, regulación del contrato laboral, alquileres baratos para los trabajadores); el acceso a la propiedad de las tierras por quienes las trabajan ${ }^{14}$; y, en suma, la europeización de la economía en aras de una necesaria industrialización, fruto de su tendencia europeizante (Tierno Galván, 1961, p. 217).

Una de las prioridades en los estudios e investigaciones realizadas por Joaquín Costa es la cuestión agraria en general, hasta el punto de convertirse en el "ideólogo de una clase supuestamente sin ideología” (Maurice \& Serrano, 1977, pp. 177-189), "la clase de los pequeños labradores" o del "campesinado parcelario" (Gómez Benito \& Ortí Benlloch, 1996, p. 35).

En ese ámbito realiza un énfasis especial en el tópico de la tenencia y titularidad de la tierra (Sanz Jarque, 1994, pp. 70-71), pues, en su opinión, la propiedad privada no es ilimitada y debería corresponder a los agricultores que la cultivan, motivo por el cual, entre otras razones, desdeñó la política desamortizadora del siglo XIX en la medida que, por su través, se produjo la consolidación del sistema oligárquico y caciquil en detrimento de los pequeños agricultores, llamados a integrar la masa neutra de la sociedad impulsora de la resurrección regeneracionista. Precisamente y, para conocer con exactitud la distribución de la propiedad de las tierras, Costa enarbola la institución del catastro territorial como instrumento imprescindible y la reforma del Registro de la Propiedad (Gómez Benito \& Ortí Benlloch, 1996, p. 345).

14 Buena parte de este ideario se recogería en su obra La tierra y la cuestión social (1912). 
En esta línea de pensamiento, Costa aboga por el colectivismo agrario ${ }^{15}$ en el que encaja la propiedad privada de los medios de producción, salvo la propiedad de las tierras, respecto de la cual se pronuncia a favor de la explotación asociativa y comunitaria.

De ahí que Costa propone un proyecto agrario modernizador (Gómez Benito \& Ortí Benlloch, 1996, p. 48), que parte de su visión crítica del orden agrario liberal de hegemonía latifundista, al que tacha de extensivo, desequilibrado, desertificante, de baja productividad y de estancamiento proteccionista. A tal fin elabora un programa de desarrollo agrario nacional regeneracionista, que pretende la reconstitución del sistema agrario desde la economía rural popular mediante el reequilibrio entre el pequeño y el gran cultivo, con una orientación librecambista extensiva. Por su través, se pretendía sustituir el liberalismo doctrinario individualista, propio de la estructura oligárquica del Estado liberal de la Restauración, por un neoliberalismo social, reformista ético, sustantivo y comunitario (Martínez Val, 1994, p. 42) en un proceso de modernización agraria desarrollado en dos fases: una primera, extensiva; y la segunda, intensiva. En virtud de este nuevo modelo se trata de alcanzar una serie de objetivos bien definidos: la implantación del colectivismo agrario; el reequilibrio entre la sociedad urbana y la rural en aras de la lucha contra la desertificación y la despoblación; y la sintonía entre la actividad humana y el respeto a la naturaleza, abogando por una política de repoblación forestal (Ballarín Marcial, 1994, pp. 109-112).

Factor clave en toda su visión sobre la modernización agrícola es el tema de la política hidráulica, planteado no como mera solución técnica a los problemas agrícolas de la España del momento, sino más bien como un verdadero proyecto político integral orientado a la regeneración agraria respecto al sistema caciquil vigente (Gómez Benito \& Ortí Benlloch, 1996, p. 41). Una política hidráulica reflejada en unos principios ${ }^{16}$, que parten de la necesaria construcción por parte del Estado de un sistema nacional de pantanos y canales y la consiguiente nacionalización de las aguas con miras a la reconversión hídrica de los cultivos a través del sistema de regadíos, la combinación de la agricultura y la ganadería, así como la reconversión, diversificación e intensificación de la práctica hortofrutícola ${ }^{17}$ en detrimento de la producción cereal (Ballarín Marcial, 1994, pp. 112 y ss.). Todo ello aderezado con la implantación de una política comercial librecambista expansiva, la reforma fiscal del crédito agrícola, el abaratamiento de los costes de los productos básicos y el complemento necesario de la política comercial y colonial. El resultado previsto de este proceso se traduciría en la configuración de un Estado social de derecho reformista e intervencionista, y en la consecución de la independencia nacional. Sin embargo, el fracaso del proyecto formulado por Costa desencadenaría en España la consolidación definitiva del Estado liberal.

Resumiendo, la obra agraria de Costa gravita en torno a tres grandes ejes (Gómez Benito \& Ortí Benlloch, 1996, p. 39): el diagnóstico de los grandes problemas económicos y sociales

15 En este sentido, su gran obra económica es El colectivismo agrario en España (1898), en donde se evidencia, por un lado, la existencia en España de una tradición agraria de carácter colectivista y, además, se pone de manifiesto una corriente económica tradicional opuesta a la propiedad privada ilimitada.

16 Estos textos se recogen bajo el título de Política hidráulica (Misión social de los riegos en España) en 1911, poco después de su muerte.

17 Empleando un grafismo más que ilustrativo y visionario de tiempos venideros, pues es el objetivo de las políticas agrícolas de la Unión Europea en la actualidad, Joaquín Costa ya abogaba en su tiempo por una agricultura "más verde que amarilla". 
de la agricultura y de la sociedad rural española de la segunda mitad del siglo XIX; el análisis de las instituciones socioeconómicas tradicionales de la sociedad rural; y, por fin, la elaboración de un programa de transformación radical de la agricultura en España. A su vez, Costa ejerce de visionario y propone un tinte ecológico de la agricultura, al reclamar (Gómez Benito \& Ortí Benlloch, 1996, p. 42) "la combinación armónica de trabajo e inteligencia, de agronomía y economía, de conocimiento práctico-local y conocimiento científico-general”; en suma, una nueva visión armónica de la agricultura para "regenerar el suelo de la patria" y "redimir al agricultor".

La visión crítica de Costa sobre la situación de la España del momento pone de manifiesto su lamento hondo y doloroso ante el atraso del país en comparación con el desarrollo de la civilización en Europa ${ }^{18}$, el continente más evolucionado en el siglo XIX tanto en lo cultural como en lo económico, incluida la agricultura, razón por la cual se muestra partidario de la "europeización, pero sin desespañolizar" (1982, vol. 4, pp. 213 y ss.), es decir, la europeización transcendente de España (López Medel, 1994, p. 58), sin dejar de mantener la esencia propia, mediante la indagación de nuestras raíces y no por mero mimetismo. A tal efecto, Costa idealiza la concepción de Europa como paradigma del desarrollo científico, filosófico, económico y ético. En otros términos y, en palabras de Unamuno, se trata de: “abrirse a Europa y enraizarse en la auténtica y viva tradición nacional, emanada del pueblo y no en las ideas estereotipadas ofrecidas en las historias oficiales, habría de ser la base de una regeneración de España” (Pérez de la Dehesa, 1967, p. 12). En suma, "mayor europeización y menor africanización".

En todo caso y, como corolario, el pensamiento económico de Costa fue cuestionado (Fernández Clemente, 1987 , p. 25) por el carácter excesivamente teórico de sus postulados; por su tibio reformismo, al no plantear verdaderos cambios estructurales; así como también por no haber tomado en consideración en la justa medida de su ideario tanto la repercusión de la industrialización, como el protagonismo progresivo y determinante del movimiento obrero en España.

\section{Interrelación del derecho y de la economía en el pensamiento de Joaquín Costa}

Como ya hemos podido constatar, tanto el derecho como la economía se encuentran entre los ámbitos de interés predilectos de Joaquín Costa a lo largo de su vida. Es cierto que, por su formación académica y profesional, enfiló al mundo del derecho su mayor dedicación y esfuerzo, lo que se tradujo en el grueso de su obra escrita; sin embargo, su gran altura intelectual le permitió recorrer escenarios dispares del pensamiento y del saber, que atrajeron su atención. Este es el caso de la economía, toda vez que el espíritu regeneracionista que él lideraba en nuestro país precisaba de un movimiento pacífico, pero decidido, por parte de las clases medias — masa neutra - que impulsara un cambio estructural, por supuesto económico, de una sociedad española cautiva del flagelo de un sistema oligárquico y caciquil a través de una revolución que, en modo alguno y en su opinión, era la abanderada por el proletariado.

18 Cabe destacar en este sentido las siguientes obras de Costa: Ideario de Costa (J. García Mercadal, 1964); Reconstitución y europeización de España (1899), reeditada por Sebastián Martín Retortillo más recientemente (1981). 
En efecto, ese movimiento que desembocaría en una nueva sociedad regenerada se reflejaría en el famoso lema escuela y despensa, en cuya virtud, la educación integral y universal de la población, junto a las políticas económicas de gran calado tendentes al desarrollo agrícola e industrial del país, se erigen en el soporte y basamento esencial del nuevo Estado regeneracionista que Joaquín Costa pregona.

Por supuesto, el derecho se convertiría, junto a otros elementos, en el brazo ejecutor del proyecto, lo cual pone de manifiesto la visión transversal y visionaria de Costa, pues ya en su época, como lo habían hecho algunos eximios ilustrados que le precedieron a finales del siglo XVIII y durante el siglo XIX ${ }^{19}$, abogó por la formación y el conocimiento integral (Cheyne, 1992, p. 138), así como por entretejer la conexión necesaria entre las distintas ramas del saber (Cheyne, 2010, pp. 107-113), no solo en el marco de un área específica, como por ejemplo las humanidades, sino entre distintas y variadas áreas (derecho, economía, educación, literatura, agricultura, ingeniería hidráulica, sociología, historia, geografía, etnografía y folklore, sociología, antropología, política), lo que reafirma su cualidad de polígrafo con la que se le identifica habitualmente por encajar perfectamente en este prototipo (Cheyne, 1987, p. 3).

\subsection{Derecho y utilidad}

Aun cuando Costa parte de que, tanto la moral, como el derecho se basan en la noción de la beneficencia, deslinda claramente ambos órdenes, toda vez que mientras la primera se agota en la beneficencia misma como fin inmediato (relación de causalidad), el derecho la transciende y se proyecta hacia otros fines en virtud de una relación de condicionalidad (1880, pp. 37, 40, 42), según la cual no existe derecho si no concurre una prestación útil para la satisfacción de una necesidad y el cumplimiento de un fin; sin embargo, Costa matiza y considera que la utilidad constituye una mera relación de medio a fin, razón que le lleva a sostener que el derecho no puede regirse por la utilidad, sino más bien al contrario, que esta habrá de subordinársele en la satisfacción de la necesidad jurídica. Por lo antedicho, ubica muy distante entre sí el derecho de la utilidad económica, toda vez que aquel recurre a la utilidad para satisfacer sus fines, lo que le lleva a diferenciar al hombre de bien, quien antes de ejecutar un acto cuestiona siempre si es justo, del hombre únicamente pragmático, por no decir perverso utilizando un eufemismo, que antepone en todo caso, frente a otros criterios, el de la utilidad del acto traducida en una contraprestación.

Para Costa (1880, pp. 44-46), el derecho se asienta en la consecución de los fines humanos al margen de la voluntad del ser humano, razón por la cual, más que un orden de condicionalidad, constituye un orden de finalidad. Aun reconociendo el autor que tradicionalmente ha existido una confusión entre el derecho y la utilidad marcada por un cierto egoísmo atribuido al primero, lo cierto es que el jurista aragonés se pronuncia enfáticamente por la connivencia entre el derecho y la utilidad, partiendo de la premisa de que "la utilidad es una categoría universal, que abraza toda la realidad", incorporando en su radio de acción, entre otras, tanto la utilidad económica como la jurídica, hasta el punto de que, en su opinión, los conflictos entre el derecho y la utilidad son más aparentes que reales, toda vez que, si bien

19 Un ejemplo de este prototipo lo encontramos un siglo antes, por ejemplo, en el ilustre venezolano universal Andrés Bello, “cerebro y corazón americanos”. En este sentido, Bernad Mainar (2017, RI §418244). 
no todo lo que es útil constituye derecho, sin embargo, todo el derecho representa utilidad, de tal suerte que "lo más justo es juntamente lo más útil" (1880, pp. 48-50), una armonía ya asomada según Costa en la filosofía estoica y asimilada con mayor elaboración por Leibnitz frente a la disociación perversa que en la práctica media entre utilidad y justicia.

Concluye Costa su visión sobre la relación existente entre la utilidad y el derecho invocando y haciendo suyo el pensamiento de Benito Jerónimo Feijoo y Montenegro, quien denostaba del error común reinante en declarar y proclamar la incompatibilidad entre utilidad y derecho, lo que, por argumento en contrario, conduce a Costa a sostener la posible conciliación entre ambos términos, derecho y utilidad, un binomio que, como podemos comprobar, entronca con el de eficacia y justicia-equidad (Bernad Mainar, 2018, II), armazón sobre el que gravita la teoría del análisis económico del derecho (AED).

\subsection{Derecho y Justicia}

La relación entre el derecho y la justicia es abordada por Joaquín Costa a propósito del principio según el cual la ignorancia del derecho no excusa de su cumplimiento, una tesis que cuestiona abiertamente, mediante la presentación de su antítesis en cuya virtud la ignorancia de la ley por falta de instrucción y educación de los ciudadanos constituye razón suficiente para eximir de su cumplimiento. Esta valiente propuesta la realiza en su escrito intitulado El problema de la ignorancia del derecho y sus relaciones: el status individual, el referéndum y la costumbre pronunciado con motivo de su discurso de ingreso en la Academia de Ciencias Morales y Políticas (el 3 de febrero de 1901) ${ }^{20}$.

En efecto, en lo que respecta al principio de que la ignorancia de la ley no excusa de su cumplimiento (nemini licet ignorare jus, nemo jus ignorare censetur, ignorantia legis neminem excusat), Costa realiza un cuestionamiento de las bases sobre las que este se asienta, cuales son, por un lado, la imputación al pueblo de la culpabilidad ante la ignorancia de la ley; y, por otro lado, la presunción con carácter iuris et de iure de que toda la población conoce las leyes. En este sentido, el polígrafo aragonés $(1901, \mathrm{I})$ sostiene que

\footnotetext{
Esta presunción se mantiene a sabiendas de que es contraria a la realidad de las cosas; a sabiendas de que es una ficción, a sabiendas de que es una falsedad, a sabiendas: Primero, de que nadie conoce todo el derecho, de que sólo una insignificante minoría de hombres sabe una parte y no grande, de las leyes vigentes en un momento dado; Segundo, de que es imposible que la mayoría, y aun esa minoría misma las conozca todas; y Tercero, de que la presunción conforme a la verdad de los hechos, conforme, por tanto, a la razón, a la justicia y a la lógica, sería cabalmente la inversa, que nadie conoce las leyes como no se pruebe lo contrario.
}

Precisamente por ello y, siguiendo con el cuestionamiento crítico en los términos señalados, Costa se reafirma en su posición al sostener que (1901, II) "podrían vivir ordenadamente los hombres en sociedad sin comercio apenas con las leyes; libres, por tanto, de la necesidad de conocerlas; y sin que, por ello, dicho se está, hubieran de chocarse entre sí las múltiples

20 Biblioteca Virtual Miguel de Cervantes. 
esferas individuales ni dejaran de formar juntas, como antes y como siempre, municipio, nación, Estado".

En todo caso, esta afirmación no ha de entenderse en modo alguno en el sentido de que una sociedad debe carecer de leyes, sino más bien al contrario; ni tampoco debe colegirse en el sentido de que todos los ciudadanos cuentan con el deber ineludible de ser doctos en derecho, sino más bien que las leyes que rigen la sociedad han de ser pocas, pero conocidas por el pueblo destinatario de las mismas que ha de cumplirlas, pues solo son verdaderas leyes las que el pueblo conoce y refrenda a través de su cumplimiento (Jiménez Hernández, 1994, p. 121).

Como exponente de su ideario krausista, Costa ensalza "el papel del status individual en el Derecho y reconoce la verdadera naturaleza de la persona, en tanto 'persona jurídica', la cual no es meramente el sujeto del derecho, sino juntamente y al par sujeto y objeto; que encierra dentro de sí los fines para que el derecho está dado, parte de los medios necesarios para realizarlos y actividad racional para aplicar éstos a aquéllos cumpliéndose a sí propio lo que se debe" (1901, III). Y es que, para el derecho, sobre el entendido de que la libertad constituye el supuesto básico de la ciencia jurídica (Martínez Val, 1994, p. 38)

[...] el individuo (al igual de las personas sociales) es, por una parte, sujeto de fines, y por otra sujeto de medios, en esta segunda posición se dice "obligado", deudor, condicionante; en la primera, "exigente", acreedor, condicionado: tiene, por tanto, derechos y obligaciones respecto de sí propio, y para cumplir esas obligaciones, una esfera de acción exclusivamente suya, inviolable, donde nadie pueda legítimamente inmiscuirse, dentro de la cual no hay ni cabe más diputado, senador, ministro, juez, magistrado, monarca o presidente que él mismo; realización práctica en ese límite de un régimen de selfgovernment "molecular" aplicando a la sociología, como es ya uso, este término de la ciencia natural tan absoluto como hayan podido soñarlo las teorías acráticas y libertaria. (1901, III)

Costa considera que en España rige la autarquía del Estado individual, de tal suerte que los poderes públicos no intervienen sino supletoriamente para compensar la falta de expresión de la voluntad por el individuo, hasta el punto de poder afirmar la existencia de un Código o Constitución del Estado individual sobre cuyo contenido el principio nemini jus ignorare licet no resultaría aplicable. Entre los contenidos del referido Código del Estado individual, y, por tanto, inmunes a la aplicación del principio ignorantia legis neminem excusat, Joaquín Costa señala la siguiente relación de derechos (1901, III):

1. Los derechos del hombre, llamados por excelencia individuales en época del autor, hoy incrementados en su ámbito de aplicación a través de la actual denominación de derechos humanos;

2. El derecho de pactar con fuerza de ley (el principio del contrato-ley);

3. El derecho de disponer libremente por testamento (el principio de la libertad testamentaria);

4. El derecho de renunciar los beneficios de las leyes obligatorias y prohibitivas, derogándolas tácitas o expresamente (no a priori, sino a posteriori, una vez ganados los derechos); 
5. La potestad de introducir una costumbre individual con fuerza de pacto (libertad de pacto, autonomía de la voluntad);

6. El derecho de hacer constar válidamente las obligaciones en cualquier forma (principio de libertad de forma);

7. El derecho de ejecutar por sí los propios contratos (principio de la relatividad del contrato);

8. El derecho de transigir y de comprometer en árbitros y amigables componedores (medios alternativos de resolución de conflictos);

9. El derecho de ocupar tierras para labor en el monte común (disfrute de bienes comunales);

10. El principio de inculpata tutela, según el cual cada individuo cuenta con la facultad de defender su persona y sus derechos, así como también la persona y los derechos de sus parientes (derecho a la tutela judicial efectiva o al debido proceso);

11. El derecho de prendar y retener (derechos de garantía en el cumplimiento de las obligaciones);

12. El derecho de constituirse libremente en concejos y cantones voluntarios con fines de cooperación (asociacionismo y cooperativismo); y, por fin,

13. El derecho de trasferir su personalidad jurídica a otros individuos o a entidades sociales (a través de la figura de la representación).

Y es que Costa confiere a la sistematización y aplicación de este Código o constitución interna, por la que se consagra la doctrina del Estado individual, la virtualidad de coadyuvar en la solución y superación del problema relativo a la ignorancia del derecho. Por ello, en consonancia con la promoción de su Estado liberal, incita a la preservación del individuo de la intervención de los poderes, incluido el judicial, si bien no por ello excluye su existencia, al considerarla una necesidad (Jiménez Hernández, 1994, pp. 122-126) ${ }^{21}$, aun cuando haya de ser regenerada a través de algunos premisas básicas entre las que destaca sobremanera la aproximación de la justicia al justiciable, en un grado que permita conciliar el idealismo de las soluciones con el pragmatismo de su efectividad. Por ello, Costa aboga por un procedimiento judicial sencillo, rápido y económico, en el que la autoridad judicial tenga atribuida facultad para intervenir en la práctica de las pruebas en virtud del principio de inmediatez que debe presidir la administración de justicia. Y es que, aunque Costa cuenta con una visión crítica de la administración de justicia patria, no deja de reconocer que la consecución de la justicia no puede verificarse sin el auxilio imprescindible de una administración judicial independiente y eficaz.

21 Las bases del sistema judicial diseñado por Costa se delinean en el apartado referido a la justica de su obra Reconstitución y europeización de España (1900, con reedición en 1982). 


\section{Visos de aproximación entre Joaquín Costa y el análisis económico del derecho (AED)}

A la hora de buscar la naturaleza del derecho, Costa lo deslinda de la religión y de la moral, y enlaza, en una esfera interna del derecho, con la noción de utilidad constituida entre los medios prestados libremente y los fines racionales que se pretenden alcanzar, en virtud de una relación en la que el cumplimiento de un fin racional depende de actos humanos, razón por la cual (1876, p. 57) "para que el Derecho aparezca, es indispensable la condición de un fin racional y que aparezca puesta por una actividad libremente determinada como causa”, sin que ello represente una contradicción en los términos, sino más bien al contrario, constituye una perfecta simbiosis en función del juego de la utilidad, tal cual sucede, por ejemplo, con las relaciones que median entre el derecho y la economía (1876, p. 58), puesto que, si se considera cada una de estas ramas del saber desde su relativo punto de vista, parecieran antagónicas y contradictorias, pero no sucede así si se examinan desde una perspectiva de interdependencia y correlación, bajo el tamiz de la utilidad.

En efecto, Costa parte de la afirmación de que el derecho es condicionalidad, dado que, a su juicio, no puede haber derecho sin la prestación de medios útiles para satisfacer una necesidad y, por ende, cumplir una finalidad. Sin embargo, el autor aragonés (1876, p. 40) se cuestiona de qué condicionalidad se trata la condicionalidad jurídica, hasta el punto de llegar a preguntarse si el derecho se configura como una rama de la economía y constituye una mera relación de utilidad, tal como señalan las tesis propias del utilitarismo y del positivismo. Ante este planteamiento, Costa rechaza la tesis por la cual la utilidad represente un criterio informador del derecho por el mero hecho de que a través del derecho se satisfagan necesidades y se logre el cumplimiento de una serie de fines. Por ello se pronuncia enfáticamente por la convivencia armónica entre el derecho y la utilidad (1880, pp. 44-46).

Veamos algunos ejemplos extraídos del pensamiento de Costa que, de algún modo y, a nuestro juicio, conectan con la base del actual análisis económico del derecho (AED), esto es, aspectos en los que el autor vislumbraba la necesidad de conjugar el conflicto entre la utilidad (eficiencia en términos del AED) y la justicia (equidad en la denominación del AED). En todos estos ejemplos la toma de decisiones en materia de políticas públicas resulta decisiva al efecto, en función del factor predominante que se adopte, ya sea la utilidad o la justicia, incluso en la época de Costa, cuando el AED no se había formulado, sin que ello signifique desconocer e ignorar los posibles antecedentes históricos del movimiento (Bernad Mainar, 2018):

1. El problema de la educación. Al igual que sucede en nuestros días, las políticas públicas deben realizar la asignación de los recursos públicos sobre la base de que nunca son suficientes y, por lo tanto, resultan escasos. Aun cuando hoy la educación es considerada una de las partidas presupuestarias más importantes en todos los países, lo cierto es que el juego de los principios de la eficiencia (utilidad) y de la equidad (justicia) encuentra en el problema educativo un caldo de cultivo abonado en la búsqueda del equilibrio necesario entre la eficiencia en el aprovechamiento de los recursos públicos, de por sí siempre escasos y limitados, y la equidad en su ejecución como elemento corrector de aquella para evitar situaciones de injusticia.

A través de un breve repaso de la visión de Joaquín Costa sobre la educación podemos entrever el eco y los atisbos del problema educativo bajo el prisma visionario que le 
conecta (Cheyne, 1992, pp. 132 y ss.), cuando menos por aproximación, con uno de los temas en los que el AED cuenta con mayor juego y recorrido.

Efectivamente, Costa concibe la reforma de la educación primaria como indispensable, hasta el punto de considerar este tramo del itinerario educativo del ser humano como el zócalo de la educación. A tal fin, propugna la propagación de la instrucción primaria entre las poblaciones agrícolas y las clases jornaleras ${ }^{22}$.

Además, en ese debido incremento expansivo de la educación dentro de la sociedad española, Costa propone la creación de escuelas nocturnas para hombres ya formados (Escuela de Adultos) con base en el voluntariado bajo la protección gubernamental, así como la creación de Misiones científicas populares con intervención de la universidad bajo la supervisión de una Dirección General de Misiones para fomentar e implantar la educación popular.

Evidentemente, para llevar a cabo tales proyectos, Costa propone el ennoblecimiento de la profesión del magisterio y la necesidad de aplicar un plan de formación de los maestros que permita el acceso a nuevas técnicas pedagógicas (actividades y procedimientos auxiliares y complementarios, como, por ejemplo, las visitas o excursiones culturales).

Vemos, pues, que Costa eleva a una posición preferente el papel de la educación en la sociedad española de la época, aquejada con el $72 \%$ de analfabetismo, en la que la educación media representa un privilegio de las clases acomodadas ${ }^{23}$.

Resulta más que ilustrativo que Costa, en su visión del problema educativo, clave y determinante en su concepción de la sociedad, establezca y reconozca la conexión inseparable del problema con la economía, tal como queda reflejado en su famosa frase "escuela y despensa" a favor de los "desheredados de la cultura", que se convertirá en uno de los eslóganes nacionales del momento, que le consagrarán en su faceta educadora.

2. El problema agrícola. Tal como se ha señalado anteriormente, el crecimiento de la economía augurado en la reforma regeneracionista formulada por Costa no se asentaba únicamente, desde una perspectiva económica, en una mayor eficiencia en la producción y explotación de las tierras, mediante la sustitución progresiva de la producción amarilla del cereal por la verde de la huerta, sino que también se veía impregnada de una dosis importante de equidad, toda vez que uno de los objetivos primordiales de la mejora de la economía, merced al motor que representaba en nuestro país el sector agrícola y rural, era la consecución de una situación más justa para el pequeño campesinado y los jornaleros agrícolas, fruto de una política pensada (Fernández Clemente, 1987, p. 24) "para la blusa y el calzón corto" con miras a la mejora ostensible de sus condiciones de vida, toda vez que "si los trabajadores, trabajando hasta el agotamiento, no pueden vivir, para qué quieren la patria, ni qué puede importarles el orden social”.

22 Ensayo sobre fomento de educación popular (1871), con motivo del concurso organizado por la Sociedad matritense de Amigos del País sobre "Método de propagar la instrucción primaria entre las poblaciones agrícolas y en las clases jornaleras".

23 Precisamente en 1876 Giner de los Ríos funda la Institución Libre de Enseñanza (ILE) con el objetivo de atajar los males de que adolece la educación en España. Joaquín Costa integra el grupo de intelectuales que forman parte de la ILE. 
3. El problema de las condiciones laborales, incluyendo las pensiones para la vejez. Probablemente, uno de los ámbitos donde el AED encuentra mayor caldo de cultivo a la hora de dirimir el conflicto entre eficiencia y equidad sea el laboral, donde se establecen las relaciones jurídicas laborales entre empresario y trabajador.

La peculiaridad de la materia laboral se agudiza por motivos varios en modo alguno desdeñables: estamos ante un derecho constitucional; forma parte del tejido de la economía nacional; se trata de un derecho fundamental de naturaleza social; lleva aparejada una serie de cuestiones complementarias de gran trascendencia y repercusión política, económica y social, tal como sucede entre otras, por ejemplo, con la prestación por desempleo, la pensión de retiro o jubilación (Moreno Moreno, 1997), e, incluso, el sistema de seguridad social.

Evidentemente, entre todos estos aspectos el juego del binomio eficiencia-equidad adquiere una importancia más que significativa, puesto que su gran costo para las arcas del tesoro público lo eleva a uno de los grandes apartados del presupuesto nacional de todos los países (Posner, 2007, pp. 518 y ss.). Ante una premisa de recursos escasos en la redistribución del gasto público, pues son pocos los Estados pródigos que puedan destinar casi ilimitadamente sus recursos a la satisfacción de estos rubros presupuestarios (ni siquiera los pequeños países petroleros cuando el precio del mercado del crudo sufre variaciones a la baja), resultan de vital transcendencia las políticas públicas y su reflejo en la legislación.

También Costa en este punto ejerce de visionario y cuenta con propuestas de avanzada para su tiempo, puesto que su vocación europeizante y, en suma, todo su ideario regeneracionista estaba llamado a concretarse en una modernización del país que traería el crecimiento económico necesario para mejorar las condiciones de vida de los españoles, e instaurar una sociedad más justa y equilibrada que la existente en la época de la Restauración, estable en lo político merced a un régimen de turno de los partidos de Cánovas y de Sagasta, pero aquejada de males seculares que constituyen una traba a todo intento de despegue y desarrollo nacional (López Medel, 1994, pp. 57-58): la oligarquía y la abultada burocracia; el descrédito del derecho y de la justicia; el analfabetismo y la incultura; la corrupción política; la ineficacia de los servicios públicos; la atonía y actitud pasiva del pueblo; el silencio de los intelectuales.

Frente a todas estas lacras nacionales señaladas, que lastran cualquier iniciativa de progreso, Costa propone la modernización de la economía, pero siempre acompañada del criterio necesario de justicia para la sociedad en general, y las clases populares y medias, en particular. A tal fin esgrime el deber de crear una legislación social que complemente el desarrollo económico ${ }^{24}$, en aspectos tan sensibles como la regulación del contrato de trabajo, para proteger al trabajador frente a los posibles abusos del empleador; la creación y consolidación del seguro social como garante del trabajador ante las vicisitudes que puedan suceder durante su vida laboral (accidentes, enfermedad); la jornada laboral legal de ocho horas; o, incluso, el diseño y establecimiento de cajas de retiro, una fórmula de previsión consistente en acumular un ahorro durante la vida laboral del 
empleado en atención al periodo de tiempo en el que cese en su actividad por razones de la edad, y poder contar así con unos ingresos suficientes para la subsistencia (Fernández Clemente, 1998, p. 9).

4. El problema del cuidado de la salud en el tiempo de la vejez. Al margen del plano humanitario que subyace ante el problema enunciado, Costa ya presenta la imbricación entre la economía y la justicia o, en términos actuales, propios del análisis económico del derecho (AED), entre eficiencia, entendida en el sentido de la utilidad, y equidad, concepto que, incluso en un plano meramente jurídico, no se desprende de su acepción ética por representar más bien un valor extrajurídico que impregna el ordenamiento jurídico, al igual que sucedía en el Derecho romano, en donde la aequitas fungía como factor corrector del rigor jurídico y antídoto frente a la injusticia (summum ius, summa iniuria $)^{25}$, replicando esta misión en nuestros días para evitar el predominio radical del criterio económico en la toma de decisiones en aras de la sublime y consagrada eficiencia, tal como suscriben algunos autores del nuevo AED, entre ellos R. H. Coase, G. Calabressi, o R. A. Possner (Bernad Mainar, 2019, pp. 13 y ss.).

En este sentido, el gran jurista aragonés (1880, p. 43) contrapone estos dos criterios - economía y justicia_, los valora y, finalmente, se pronuncia abiertamente en aras de la justicia, en detrimento de soluciones más economicistas guiadas de pragmatismo: "Un anciano postrado en el lecho de muerte, sometedlo a los cálculos de la economía: no puede darse hecho que le sea más contrario: ¿y qué hombre, por mucho que haya descendido en la escala de la perversidad, votará la muerte o el abandono de ese anciano, estimándolo acto de justicia?”.

5. El problema del cuidado de la salud en el caso de enfermedades incurables. Serviría el argumento invocado en el caso anterior de la vejez y el cuido de la salud en esta última fase de la vida del ser humano para el supuesto aquí planteado, ante la conveniencia o no desde un plano económico de asignar recursos a la atención de los pacientes que sufren enfermedades crónicas, pues, como señala Costa, la respuesta del positivismo para sostener dicho tratamiento y cuidado solo podría invocarse bajo el entendido de que incluso los derechos humanos se basan en la utilidad, hasta el punto de que (1870, p. 43): "Si bien el enfermo es inútil cuando la enfermedad le acosa, puede llegar a un estado de salud que recompense los beneficios que recibe de la sociedad", una solución estrictamente pragmática basada en la optimización de los recursos ante la expectativa probable de la reversión y multiplicación de los costes acarreados. Frente a esa argumentación, Costa empodera el valor de la justicia ante la mera economía, pues, en su opinión, por un lado, la conciencia social concede igual derecho a la salud tanto al enfermo incurable, como al que se halla convaleciente; $y$, a mayor abundamiento, porque en modo alguno "aparece el derecho cualificado por la utilidad; en ninguna parte lo hacemos depender de una condición de reciprocidad o de mutualidad de servicios".

6. El problema de la infancia y de la niñez. Un sector de la población tan vulnerable como el de la infancia y el de la niñez no pasa desapercibido como tema de reflexión para Joaquín Costa. Así es, invocando argumentos que van más allá del mero sentimiento

25 D. $43,26,2$ y 15. 
humanitario, toma partido de manera decidida en torno a la relación que media entre los parámetros de la utilidad y de la justicia, en cuya balanza sopesa esta última en mayor medida ante los intereses que concurren en el conflicto que se plantea entre ambos elementos del binomio (eficiencia y equidad), pues a su juicio (1880, p. 43): "A nadie puede ser útil un recién nacido: ¿y quién no se siente obligado para con él? por ninguna parte aparece el derecho cualificado por la utilidad; en ninguna parte lo hacernos depender de una condición de reciprocidad o de mutualidad de servicios".

7. El problema de la discapacidad. Con base en los mismos argumentos esgrimidos en el supuesto del cuidado de la salud para el caso de enfermedad, o de la protección de la infancia y de la niñez, Costa se pronuncia por la prevalencia de la justicia o equidad, evitando su condicionamiento determinante por razones de utilidad. Y en este sentido proclama que (1880, p. 43): "En igual caso que el enfermo y que el niño se encuentran el loco. Por ninguna parte aparece el derecho cualificado por la utilidad; en ninguna parte lo hacemos depender de una condición de reciprocidad o de mutualidad de servicios".

8. El problema del alquiler barato para la clase obrera. La vivienda constituye una de las necesidades básicas del individuo, junto a la alimentación, la educación y la sanidad. La mayoría de los textos constitucionales reconocen el derecho a una vivienda digna y adecuada (artículo 47 CE, 1978). A tal efecto, los poderes públicos participan y costean la construcción de viviendas destinadas a la venta y al alquiler. Pues bien, Costa ya se planteó este tema como consecuencia de su visita a París con motivo de la Exposición Universal de 1867, una experiencia que le marcó toda su vida ${ }^{26}$, en la medida que, deslumbrado ante una nueva realidad, pudo establecer comparaciones dolorosas con la realidad nacional (Cheyne, 2010, pp. 51 y ss.).

A propósito del éxodo masivo a las ciudades originado por la revolución industrial y la consiguiente saturación de las zonas periféricas de las grandes urbes, Costa expresa en esta obra su pensamiento, sus experiencias a raíz del viaje a París y, sobre todo, su propuesta en torno a la conveniencia y necesidad de construir viviendas sociales a los fines de proporcionar techo y cobijo a las clases trabajadoras por necesarias, premisa indispensable, a su juicio, ante el reto de acometer y poner en práctica la expansión industrial (Fernández Clemente, 1987, p. 24; Costa Martínez, 1999).

Una posición que conecta de alguna manera con la intervención de los poderes públicos propuesta por Costa en la prestación de los servicios públicos, un postulado que proclama entre los enunciados prácticos de su programa regeneracionista (Fernández Clemente, 1998, p. 9): el "selfgovernment local", o "municipalización de servicios públicos y de ciertas industrias o comercios (tranvías, teléfonos, alumbrado, baños, lavaderos, fuerza motriz, tahonas, carnicerías, hielo, etc.)".

26 La estancia de Costa en París, apenas de nueve meses, se tradujo en varios escritos no publicados remitidos por Costa a El espiritu católico y Revista de caminos vecinales (Cheyne, 2010, pp. 57-58). Los remitidos a esta última fueron publicados bajo otra firma con el título "Las habitaciones de alquiler barato" a lo largo de 1868 (números 1-6). Este será el germen de la obra Las habitaciones de alquiler barato en la Exposición Universal de París en 1867 (1868). Estos escritos se publican por la Biblioteca Costa en un volumen de no gran calidad bajo el título Instituciones económicas para obreros. Las habitaciones de alquiler barato en la Exposición Universal de París en 1867. En nuestros días, la obra se ha publicado por la Institución "Fernando el Católico", Zaragoza, (1999). 
9. El problema del sistema penal. Siguiendo las huellas del liberalismo político (J. Locke), del liberalismo económico (A. Smith) y del utilitarismo filosófico (J. Bentham), el tema de la población reclusa y de los penados, por lo que al sostenimiento y financiación de los presidios se refiere, constituye un asunto digno de consideración ante la potencial utilidad que la sociedad pueda obtener de los reclusos mediante algún tipo de compensación.

Ya Beccaría (1738-1794) en su obra De los delitos y las penas analiza los delitos y las penas desde un punto de vista economicista, según el daño y el provecho que acarrean a la sociedad, de tal forma que los problemas jurídicos, incluidos los penales, se abordan según pautas y coordenadas económicas.

En la actualidad buena parte de las leyes penales y de las políticas criminales tienen en cuenta, junto a otros factores, su impacto económico, lo cual encuadra al derecho penal en el ámbito del AED (Posner, 2007, pp. 343 y ss.; Shavell, 2016, pp. 527 y ss.).

Algunos autores proponen una política criminal rentable que maximice el combate de la sociedad frente al flagelo de la delincuencia (Becker, 1974, pp. 1 y ss.) y, en tal sentido, se propone que el coste económico ha de ser tenido en cuenta a la hora de diseñar y adoptar políticas criminales, toda vez que la comisión de un delito irradia sus efectos en varias direcciones: hacia la víctima, el victimario y la sociedad. Sin embargo, claro está, este enfoque puramente economicista en aras de una pretendida eficiencia, entra en colisión con el valor de la justicia, en temas tan polémicos, por ejemplo, como la pena de muerte, o el de la conveniencia de evitar el confinamiento de los delincuentes en lugares de reclusión, ante su elevado costo para la sociedad, cuestionando así incluso la posible reinserción del delincuente, ante la escasa rentabilidad económica y social que pudiera reportar, llegado el caso, la pena privativa de libertad (Ehrlich, 1975, pp. 397 y ss.).

Pues bien, tampoco este asunto pasó desapercibido para un concienzudo Costa, quien sobre el particular proclama (1880, p. 43): "el culpado, por ninguna parte aparece el derecho cualificado por la utilidad; en ninguna parte lo hacemos depender de una condición de reciprocidad o de mutualidad de servicios; antes bien, cuando un hombre, equivocando más o menos conscientemente el camino, sacrifica sus deberes para con los demás en aras de lo que estima ser su utilidad, decimos que ha cometido una injusticia o un delito".

10. El problema de la administración de justicia. El tiempo en derecho, más que oro, es justicia; de ahí que las demoras judiciales no solo perjudican al más débil económicamente a la espera de una respuesta favorable, sino que también lo constriñen a un mayor estado de indefensión, ante la imposibilidad de mantener en el tiempo la dilación de los procesos judiciales hasta alcanzar una sentencia firme y definitiva. Costa, litigante en el foro, conoce el estado de la administración de justicia en España, lo que le impulsa a denostarla con acritud y severidad. Por tal motivo, en su propuesta de regeneración del poder judicial aboga, entre otros postulados, por la implantación de un procedimiento judicial sencillo, rápido y económico (Jiménez Hernández, 1994, p. 124), que sirva como instrumento de defensa accesible, y que no se convierta en una rémora a su verdadera y primordial finalidad — dictar justicia — en función del factor económico y cultural de los justiciables. 
Así pues y, a modo de síntesis, de todos estos ejemplos planteados por Costa podemos extraer la conclusión de que el polígrafo aragonés siempre se pronunciaría del lado de la justicia, al entender que solo lo justo resulta en verdad útil, criterio que replica y transfiere también al ámbito político en la toma de decisiones, incluida la legislación elaborada para ponerlas en práctica. Por tal motivo, trae a colación y ensalza los valores de la Grecia clásica cuando nos recuerda a Demóstenes sobre el particular (1880, p. 45) 27: "aquel insigne orador, honra de la raza aria, que condensó en sí el espíritu de la Grecia, próximo a extinguirse, después de sublime efusión por el mundo oriental, adelantó ya, en el más elocuente de sus discursos, que la política debe regirse por principios de justicia, y no por principios de utilidad".

Evidentemente, aun cuando debemos realizar el oportuno ajuste cronológico e histórico actual con la segunda mitad del siglo XIX e inicios del siglo XX en España, lo cierto es que Joaquín Costa ya atisbó el punto sobre el que se iba a desarrollar siglo y medio después el análisis económico del derecho (AED), al contraponer los conceptos de utilidad y justicia en el ámbito del derecho, y establecer, así, la oportuna relación entre el derecho y la economía, a propósito de ciertos temas de su tiempo que, sin grandes estridencias y argumentos forzados, podrían trasladarse perfectamente hasta nuestros días.

El criterio de la eficiencia social (Casalmiglia, 1989, pp. 113-151) determina la relación entre el derecho y la economía en la toma de decisiones relativas a la asignación y distribución de recursos, limitados por su naturaleza (Doménech Pascual, 2014, pp. 104-105, 120-122). La disyuntiva entre eficiencia y equidad se salda a favor de la primera en el AED (Posner, 1983, p. 2; Coleman, 1988, p. 95), de tal suerte que, ante una situación determinada, una acción será eficiente cuando incremente los provechos y aminore los costos, en tanto que será equitativa cuando haga disminuir la diferencia de los beneficios distribuidos entre los miembros de la comunidad considerada.

El AED irradia su proyección a diversos campos de la investigación de nuestros días (Ibáñez Jiménez, 2011, pp. 170 y ss.), tanto en materias de derecho privado (contratos, responsabilidad social corporativa, elección pública y economía de la regulación administrativa, derecho de la competencia, derecho concursal, consumidores y usuarios, seguros, derecho de daños), como de derecho público (derecho laboral, derecho penal, derecho de la seguridad social, derecho procesal, derecho tributario, derecho administrativo). Ello denota su transversalidad y multifuncionalidad, características tan relevantes que lo individualizan, empoderan y siguen justificando su presencia en nuestras vidas en pleno siglo XXI: el progreso y bienestar alcanzados se enfrentan ante el reto nada desdeñable de su sostenibilidad en el tiempo, toda vez que, por un lado, contamos con una población en continuo crecimiento; y, por otro, con unos recursos limitados que deben ser sabiamente administrados. Surge así la necesidad de pergeñar una nueva concepción de la economía y de las políticas públicas que permitan conciliar y equilibrar las paradojas y desajustes que la sociedad del bienestar y de la abundancia ha ido dejando a su paso.

Costa, una vez más visionario, conecta el derecho y la economía para alertar del posible conflicto entre la justicia y la utilidad. Y de ahí, su doble mérito: el haber detectado este

27 Discurso pro Corona. También en Quintiliano, Institutio oratoria $(2,15)$, donde se señala que el orador debe ser hombre justo; y Ciceron, De officiis, $(1,45)$, cuando expresa que no debe cometerse una acción torpe o inmoral, ni siquiera para salvar a la patria. 
punto de fricción como base de los problemas padecidos en la España de la época; y el haber acertado al plantear la regeneración del equilibrio perdido a través de la justicia, en una sociedad guiada por un mal entendido principio de utilidad.

\section{Conclusión}

Según Joaquín Costa el derecho se asienta en la consecución de los fines humanos al margen de la voluntad del ser humano, razón por la cual, más que un orden de condicionalidad, constituye un orden de finalidad. Aun así, se pronuncia enfáticamente por la connivencia entre el derecho y la utilidad, sin que ello represente una contradicción en los términos, sino más bien al contrario, una perfecta simbiosis, al igual que sucede con las relaciones que median entre el derecho y la economía.

Costa, adelantándose una vez más a su tiempo, conecta el derecho y la economía para alertar del posible conflicto entre la justicia y la utilidad, un binomio que, como sabemos, entronca con el de eficacia y justicia-equidad, armazón sobre el que gravita la teoría del análisis económico del derecho (AED), que pretende explicar y diseñar el derecho a través de una perspectiva económica, ante el reto que supone satisfacer un amplio abanico de necesidades mediante la debida administración de unos recursos limitados.

Costa avizora el concurso de la utilidad y de la justicia en los problemas de su tiempo y así lo subraya: la educación, la producción agrícola, la salud en la vejez, la infancia y la niñez, el trato de las enfermedades incurables, la discapacidad, las relaciones laborales, la legislación social, los alquileres sociales, o la administración de justicia. En todos estos ejemplos Costa siempre se pronuncia del lado de lo justo, por entender que solo lo justo resulta en verdad útil, un criterio que replica y transfiere también al ámbito político en la toma de decisiones, incluida la labor legislativa que deba llevarlas a efecto.

Así pues, Costa logra captar este punto de fricción en la base de algunos de los problemas de su época y se decanta por plantear la regeneración a través de la justicia, frente a una sociedad habitualmente conducida por el principio de la utilidad.

\section{Bibliografía}

Ballarín Marcial, A. (1994). Joaquín Costa hoy. Vigencia del pensamiento de Joaquín Costa. Madrid: Gobierno de Aragón. Casa de Aragón en Madrid.

Becker, G. S. (1974). Crime and punishment: an economic approach. En G. S. Becker, \& W. M. Landes, Essays in the economics of crime and punishment (pp. 1-54). National Bureau of Economic Research. Recuperado de: http:/ /www.nber.org/chapters/c3625.pdf (última consulta 24/04/2020).

Bernad Mainar, R. (2017). Andrés Bello: el hombre, el ilustrado, el jurista. e-Legal History Review. Studia Legalia Hispanica Rescripta. Iustel, 24 (RI \418244).

Bernad Mainar, R. (2018). Retrospectiva histórica del análisis económico del derecho (I): orígenes más remotos y huellas posteriores. Icade. Revista de las Facultades de Derecho y Ciencias Económicas y Empresariales, 105. doi: 10.14422/icade.1105.y2018.008 (última consulta 23/04/2020). 
Bernad Mainar, R. (2019). Retrospectiva histórica del análisis económico del derecho (II): desde el viejo al nuevo análisis económico del derecho. Icade. Revista de las Facultades de Derecho y Ciencias Económicas y Empresariales, 106. doi: 10.14422/icade.1106.y2019.006 (última consulta 23/04/2020).

Bobbio, N. (2018). Iusnaturalismo y positivismo jurídico. Madrid: Trotta.

Calsamiglia, S. (1989). Justicia, eficiencia y optimización de la legislación. Documentación Administrativa, 218-219, 113-151. doi: 10.24965/da.v0i218-219.5136.

Capellán de Miguel, G. (1998). La renovación de la cultura española a través del pensamiento alemán: Krause y el krausismo. BROCAR, 22, 137-153. doi: 10.18172/brocar.1737.

Chacón Delgado, P. J. (2013). Historia y nación. Costa y el regeneracionismo en el fin de siglo. Santander: Universidad de Cantabria.

Cheyne, G. J. G. (1987). El hombre. ¿Por qué fue importante Costa? Cuadernos Altoaragoneses de Trabajo, 7, 3-6. Huesca: Instituto de Estudios Altoaragoneses. Excma. Diputación Provincial de Huesca.

Cheyne, G. J. G. (1992). Joaquín Costa y la educación. En G. J. G. Cheyne, \& A. Gil Novales (eds.), Ensayos sobre Joaquín Costa y su época (pp. 127-149). Huesca: Fundación Joaquín Costa. Instituto de Estudios Altoaragoneses.

Cheyne, G. J. G. (2010). Joaquín Costa, el gran desconocido. Barcelona: Ariel Historia.

Coleman, J. L. (1988). Efficiency, Auction and Exchange. Markets, Morals and the Law (pp. 67-94). Cambridge: Cambridge University Press. doi: 10.1093/ acprof:oso/9780199253609.003.0003.

Costa Martínez, J. (1876). La vida del derecho. Madrid: Imp. Aribau.

Costa Martínez, J. (1880). Teoría del hecho jurídico individual y social. Madrid: Imprenta de la Revista de Legislación.

Costa Martínez, J. (1901). El problema de la ignorancia del derecho y sus relaciones: el status individual, el referéndum y la costumbre. Biblioteca Virtual Miguel de Cervantes. Recuperado de: http:/ / fama2.us.es/fde/problemaDeLaIgnorancia.pdf (última consulta 13/04/2020).

Costa Martínez, J. (1912). La tierra y la cuestión social. Obras completas. Tomo IV de la Biblioteca económica. Madrid: Biblioteca Costa.

Costa Martínez, J. (1981). En S. Martín Retortillo (ed.), Reconstitución y europeización de España y otros escritos. Madrid: Instituto de Estudios de Administración Local.

Costa Martínez, J. (1982). Obras de Joaquín Costa. 12 volúmenes. Zaragoza: Guara Editorial.

Costa Martínez, J. (1999). Instituciones económicas para obreros. Las habitaciones de alquiler barato en la Exposición Universal de París en 1867. Zaragoza: Institución "Fernando el Católico".

Costa Martínez, J. (2005). Obra politica menor (1868-1916). Huesca: Fundación Joaquín Costa. Instituto de Estudios Altoaragoneses.

Costa Martínez, J. (2009). La tierra y la cuestión social. Edición crítica, estudio introductorio y notas de C. Gómez Benito y A. Ortí. Madrid: CIS-BOE. 
Doménech Pascual, G. (2014). Por qué y cómo hacer análisis económico del derecho. Revista de Administración Pública, 195, 99-133.

Ehrlich, I. (1975). The deterrent effect of capital punishment: a question of life and death. American Economics Review, 65(3), 397-417.

Fernández Clemente, E. (1998). El pensamiento y la obra de Joaquín Costa. Barcelona: Institut de Ciènces Politiques y Socials.

Forcadell Álvarez, C. (1987). El político. ¿Por qué fue importante Costa?. Cuadernos Altoaragoneses de Trabajo n. ${ }^{\circ}$ (pp. 25-28). Huesca: Instituto de Estudios Altoaragoneses. Excma. Diputación Provincial de Huesca.

García Mercadal, J. (1964). Ideario de Costa y otros escritos. Madrid: Aguado.

Gil Novales, A. (1965). Derecho y Revolución en elpensamiento de Joaquín Costa. Madrid: Península.

Gómez Benito, C., \& Ortí Benlloch, A. (1996). Estudio crítico, reconstrucción y sistematización del corpus agrario de Joaquín Costa. Huesca: Fundación Joaquín Costa. Instituto de Estudios Altoaragoneses.

Ibáñez Jiménez, J. W. (2011). Análisis Económico del Derecho. Método, investigación y práctica jurídica. Barcelona: Bosch.

Jiménez Hernández, J. I. (1994). Costa y la justicia. Vigencia del pensamiento de Joaquín Costa (pp. 119-140). Madrid: Gobierno de Aragón. Casa de Aragón en Madrid.

Kremer-Marietti, A. (1980). L'Anthropologie positiviste d'Auguste Comte. París: Librairie Honoré Champion.

Lissorgues, Y. (1998). La crisis de fin de siglo. El regeneracionismo. En V. García de la Concha (dir.), Historia de la literatura española, 9 (pp. 46-58). Madrid: Espasa Calpe.

López Medel, J. (1994). Joaquín Costa y el pueblo. Vigencia del pensamiento de Joaquín Costa (pp. 47-65). Madrid: Gobierno de Aragón. Casa de Aragón en Madrid.

Mainer Baqué, J. C. (1987). El literato. ¿Por qué fue importante Costa?. Cuadernos Altoaragoneses de Trabajo n. 7 (pp. 11-16). Huesca: Instituto de Estudios Altoaragoneses. Excma. Diputación Provincial de Huesca.

Martínez Val, J. M. (1994). Joaquín Costa en la libertad. Vigencia del pensamiento de Joaquín Costa (pp. 31-45). Madrid: Gobierno de Aragón. Casa de Aragón en Madrid.

Maurice, J., \& Serrano, C. (1977). J. Costa: Crisis de la Restauración y populismo (1875-1911). Madrid: Siglo XXI de España.

Moreno Moreno, M. C. (1997). Análisis económico del sistema de pensiones públicas. Documentos de Trabajo de la Facultad de Ciencias Económicas y Empresariales, 13, 41. Universidad Complutense de Madrid.

Navarro Rubio, M. (1994). Don Joaquín Costa, académico de la de Ciencias Morales y Políticas. Vigencia del pensamiento de Joaquín Costa (pp. 21-30). Madrid: Gobierno de Aragón. Casa de Aragón en Madrid. 
Pérez de la Dehesa, R. (1967). Política y sociedad en el primer Unamuno: 1894-1904. Madrid: Ciencia Nueva.

Pino Díaz, F. del (1987). El antropólogo. ¿Por qué fue importante Costa?. Cuadernos Altoaragoneses de Trabajo n 7 (pp. 28-32). Huesca: Instituto de Estudios Altoaragoneses. Excma. Diputación Provincial de Huesca.

Posner, R. A. (1983). The Economics of Justicie. Cambridge: Harvard University Press.

Posner, R. A. (2007). El análisis económico del derecho (2 edición). México: Fondo de Cultura Económica.

Sanz Jarque, J. J. (1994). La cuestión de la tierra y las cooperativas agrarias en el pensamiento de Joaquín Costa, hoy. Vigencia del pensamiento de Joaquín Costa (pp. 71-93). Madrid: Gobierno de Aragón. Casa de Aragón en Madrid.

Shavell, S. (2016). Fundamentos del análisis económico del derecho. Madrid: Editorial Universitaria Ramón Areces.

Tierno Galván, E. (1961). Costa y el regeneracionismo. Barcelona: Barna S. A.

Vallet de Goytisolo, J. (1994). Prólogo. Vigencia del pensamiento de Joaquín Costa (pp. 13-17). Madrid: Gobierno de Aragón. Casa de Aragón en Madrid. 